problem and to the trainee, but those engaged particularly in thoracic surgery will also find a great deal to entertain and sometimes instruct them.

M.M.B.

\section{MODERN TRENDS IN UROLOGY}

Edited by E. W. Riches, M.C., M.S., F.R.C.S. Pp. xiii +476 with 217 illustrations, 2 in colour. London: Butterworth \& Co., I $953.75 \mathrm{~s}$.

The need for a modern text-book of urology has long been felt. 'Modern Trends in Urology,' edited by Riches and contributed to by many of the leaders of urology in this country, very largely fulfils this need.

All the important subjects in urology are discussed. In some cases the discussions are not always along generally accepted lines, but the emphasis is always on recent thought and on future possibilities, such as is revealed in the section on homotransplantation of the kidney. Recent aids to diagnosis such as lumbar aortography and perirenal air insufflation are described in detail. The value of the thoraco-abdominal approach to the kidney in cases of neoplasm is stressed. The place of radiotherapy and the use of radio-active isotopes in urology is discussed. A considerable account of the use and value of the various chemotherapeutic agents effective against tuberculosis is given.

The section on carcinoma of the prostate devotes some space to the operation of total prostatectomy. Cases suitable for such treatment are certainly the exception, and it is a pity that no mention is made of Huggins' work of bilateral adrenalectomy for advanced cases of carcinoma of the prostate, which are all too common.

It is also to be regretted that the work is confined to urology and that genital diseases are not discussed. Of necessity this would have increased the size of the work, but it would also have added to its value, and 'Modern Trends in Urology' is certainly not the biggest of the series.

To those who have been fortunate enough to be able to attend the meetings of the British Association of Urological Surgeons to whom the work is dedicated, or the meetings of the Urological Section of the Royal Society of Medicine or the lectures at the Royal College of Surgeons, many of the articles will be familiar. It is, however, most convenient to have these articles collected together and edited. To those who have not been so fortunate and who have any interest in urology this work can be recommended without reserve.

\section{J.W.P.G.}

\section{TEXTBOOK OF PHYSIOLOGY AND BIOCHEMISTRY}

By G. H. Bell, B.Sc., M.D., F.R.F.P.S.G., F.R.S.E., J. N. Davidson, M.D., D.Sc., F.R.F.P.S.G., F.R.I.C., F.R.S.E., and H. ScaRBOROUGH, M.B., Ph.D., F.R.C.P.E. Second edition. Pp. xii + 1002, illustrated. Edinburgh: E. \& S. Livingstone, Ltd. I 953 . 5os.
The second edition of this book appears three years after the first and is suitably revised. It is intended as an introductory text to physiology and $\mathrm{P}$ biochemistry, especially for medical students begin $c$. ning their studies, and it is not intended to serve the student who has advanced beyond the elementary stages. Bearing in mind this aim of the book, it if to be regretted that it does not contain a more adequate account of the fundamental physico $\frac{\bar{W}}{7}$ chemical principles of the subject. Most medica $\mathbb{B}$ students are ill equipped in this branch of know ledge when they begin to learn physiology and bio-s chemistry and this severely limits their ability to comprehend these subjects. A much fuller account of the physiological chemistry of the body fluids, $\vec{\omega}$ including osmotic pressure, acid-base balance, and electrolyte metabolism, would enhance the value ofo the book and bring it more into line with contem 3 . porary publications, especially those from Northi American sources. That the authors have devoted five lines each to the metabolism of sodium and potassium, while there are five pages of text devoted to vitamin $C$, seems to be a serious source of imbalance in a book devoted to first principles. Tableo 22 (I) contains an error in that the blood chloride values recorded are actually those which pertain to the normal serum chloride concentrations.

Although the importance of Claude Bernard's induction, ' La fixité du milieu intérieur est la con-dition de la vie libre, independante,' is referred toD in the introduction, the principles of biologien $\Gamma$ regulation and homoiostasis generally seems sufficiently stressed in the text.

This book in its first edition was well receive $d$ and, despite present criticism, deservedly so. It iso easy to read, printed on excellent paper and profusely illustrated.

V.W.

\section{THE MEDICAL ANNUAL 1953}

Edited by Sir Henry Tidy, K.B.E., M.A., M.D., F.R.C.P., and A. Rendle Short, M.D., B.S. B.Sc., F.R.C.S. Pp. xvi +513 , with 100 . illustrations. Bristol: John Wright \& Sons Ltd.,을 1953. 27s. 6d.

For doctors among the compensations for the passing of the years is the perennial satisfaction which one is certain to feel with each newo issue of this favourite. This year the editors have again assembled an authoritative and comprehensiveo review of recent progress in every branch of medicine.

New drugs such as isonicotinic hydrazide and the methonium compounds are filling empty places in treatment; the practical applications of cortisone $\mathrm{N}$ are becoming clearer. The surgery of the heart, great vessels and of the pancreas are subjects of $\omega$ increasing experience, and many valuable contributions in these and other surgical sections serve aso an up to date statement on progress in these fields $\frac{-}{\widetilde{C}}$ and also afford a survey of the more importanto literature.

Your reviewer is not familiar with abiotic sub- 